\title{
Scriptorium
}

http://dx.doi.org/10.15448/2526-8848.2019.2.32259

\section{O sampling como ação afrodiaspórica nas canções de Criolo e Emicida}

\author{
The sampling as afrodiasphoric action in Criolo \\ and Emicida's songs
}

Alexandre Carvalho Pitta'

\begin{abstract}
Resumo: Este trabalho tem como objetivo estudar as articulações entre concepções da canção popular urbana e a obra musical dos rappers Criolo e Emicida. Para essa abordagem, discutiremos, partindo de amostras de letras de música, a bricolagem como processo que desenvolve uma forma diferenciada de canção, que, nos artistas, está ligada ao gênero musical que os consagrou: o rap. Traçando eixos comparativos entre a bricolagem e o sampling, método que está na base das canções de rap, buscamos compreender como essa dinâmica interfere nas interpretações sobre a canção popular brasileira. Atrelado esse processo de recorte e colagem, Criolo e Emicida se colocam no lugar de fala do afrobrasileiro, a partir de uma perspectiva afrodiaspórica, evidenciando, no âmbito da música brasileira, os efeitos de um projeto de modernização no país que trouxe o desenvolvimento às custas do aumento das desigualdades sociais, cujos choques tornam-se evidentes em suas obras.
\end{abstract}

Palavras-chave: MPB; Criolo; Emicida; Rap; Bricolagem; Canção popular; Sampling.

Abstract: This paper aims to study the articulations between conceptions of urban popular music and the musical work of rappers Criolo and Emicida. Considering this approach, we will discuss, starting from samples of lyrics, bricolage as a process that develops a differentiated form of song that, in Criolo and Emicida's body of work, is linked to the rap music, the genre that made them famous. Tracing comparative axes between the bricolage and the sampling, a method that underlies rap songs, we try to understand how this dynamic interferes with the interpretations of Brazilian popular music. Attached to this process of cutting and pasting, Criolo and Emicida creates from an AfroBrazilian point of view, showing, in the Brazilian music context, the effects of a modernization project in Brazil, that brought development at the expense of the increase of social inequalities, whose tensions became clear in their works.

Keywords: MPB; Criolo; Emicida; Rap; Bricolage; Popular song; Sampling.

O rap mobiliza-nos a pensar a canção popular urbana como espaço de inscrição do discurso afirmativo afrobrasileiro. Para tanto, neste artigo, iremos analisar a linguagem do rap e sua vinculação a uma perspectiva afrodiaspórica, que constrói um lugar de fala e um espaço performático de vivência para os afrobrasileiros, e como esse espaço performático é construído por Criolo e Emicida em suas respectivas produções cancionais. Discutiremos também como a linguagem cancional do rap construída nas canções dos rappers oportunizam uma leitura a contrapelo da história e da identidade afrobrasileira, a partir das relações estabelecidas entre melodia e letra, promo- 
vendo uma resistência da lógica racista e exploratória que acompanha a formação da sociedade brasileira.

Para compreendermos o papel do rap no Brasil contemporâneo e situarmos Criolo e Emicida nessa produção musical, é necessário observar o contexto de emergência do hip hop nos EUA. Como estratégia de fuga de uma crise social e econômica que atingiu a Jamaica no início dos anos 70, jovens jamaicanos migraram para os EUA, levando consigo a experiência do dub:

O dub foi a maneira que os produtores musicaise os engenheiros de som jamaicanos inventaram, desde meados dos anos 60, para fazer música e pensar a música. As canções deixaram de ser encaradas de maneira linear. Os sons passaram a ser montados não-linearmente, antecipando a maneira de editar textos/barulhos/imagens (o cortar-e-colar, ou cut-and-paste) que se tornou dominante a partir da personalização dos computadores. (VIANNA, 2003)

No início dos anos 50, a influência cultural estadunidense na Jamaica se manifestava no $R \& B$ produzido nos EUA e exportado também por esse país. Nesse contexto, o dub surgejunto aos sistemas de som, criados por conta do alto custo de se contratar uma banda para as dancehalls. Inovações tecnológicas importantes criadas por produtores e engenheiros de som jamaicanos, como Coxsone Dodd, King Tubby e Lee "Scratch" Perry, abriram caminhos para a intervenção do cantor ou DJ em uma batida já gravada, permitindo os toasts - performance vocal durante a execução das músicas, próxima ao hoje conhecido canto falado do rap.

O dub não é no seu momento de origem visto como um estilo, um gênero, ele é uma manipulação de sons já existentes feitas por produtores que buscam reciclar gravações e adaptá-las para outros usos mais livres e espontâneos, na maioria das vezes realizados no ambiente do sound system. [...]

Tem-se, então, de um lado o sound system e do outro o estúdio, estes são os principais locais onde acontecem a música jamaicana. O dub na Jamaica apenas faz sentido ao ser compreendido dentro desta relação, dentro deste eixo estúdio sound system. (MUNIZ, 2010, p. 59-60)

Dialogando com o pensamento de Hermano Vianna, temos a ampliação do dub, não sendo enquadrado como apenas um gênero musical, mas um modo de se pensar a música, um procedimento para transformar uma música. Agenciando fragmentos de canções, linhas de instrumentos, efeitos e linhas vocais, o dub apropria-se de produções preexistentes e abre caminho para um amplo universo musical, em que a música eletrônica, o rap e o reggae são alguns dos gêneros musicais que emergem desse pensamento filosófico-musical. E essa herança potente e vertiginosa presente no dub será determinante - no âmbito musical, cultural e político - para a produção cancional do rap.

Com os imigrantes jamaicanos e a cultura dos sistemas de som, o movimento hip hop começa a surgir nos EUA dos anos 70. Nesse período, o viés étnico e político do movimento ganha força, tendo como um dos principais agenciadores dessa guinada política Afrika Bambaataa. Com o objetivo de dar ao hip hop uma importância política para os negros dos/nos EUA, além dos conhecidos "quatro elementos" do hip hop - DJ, MC, break e grafite -, ele acrescentou um quinto: o conhecimento. Com isso, a produção musical da diáspora africana passa a ter o rap como um dos principais expoentes na exposição e performativização de afrodescendentes. Aspectos como a oralidade e o corpo como linguagem fizeram com que o movimento se expandisse para outros países e instigassem uma tomada de consciência daqueles que passaram a se reconhecer nesse espaço simbólico afrodiaspórico. Assim, a perspectiva da Paul Gilroy acerca do movimento da diáspora permite uma análise que enxerga o poder de apropriação e de intercâmbios entre diversas comunidades expatriadas do continente africano e postas em contato entre si e com outros grupos sociais.

O Atlântico Negro como potencialização da cultura negra em situação de diáspora é uma máquina simbólica que mobiliza afetos e se constrói em diferentes sujeitos de diferentes países. Essa maquinaria elabora - nos choques étnicos, sociais e culturais - uma metafísica da negritude (GILROY, 2001), que 
parte da apropriação e da re-escritura de sua existência para produzir linguagens, sentidos e resistência:

Como foi possível a apropriação dessas formas, estilos e histórias de luta em tão grande distância física e social é, por si só, uma questão interessante para os historiadores culturais. Ela foi facilitada por um fundo comum de experiências urbanas, pelo efeito de formas similares - mas de modo algum idênticas - de segregação racial, bem como pela memória da escravidão, um legado de africanismos e um estoque de experiências religiosas definidas por ambos. Deslocadas de suas condições originais de existência, as trilhas sonoras dessa irradiação cultural africanoamericana alimentaram uma nova metafísica da negritude elaborada e instituída na Europa e em outros lugares dentro dos espaços clandestinos, alternativos e públicos constituídos em torno de urna cultura expressiva que era dominada pela música. (GILROY, 2001, p. 175)

No Brasil, o movimento hip hop se fortalece a partir da segunda metade dos anos 80 , com os bailes black no Rio de Janeiro e São Paulo. Estando o soul, $R \& B$ e principalmente o funk já presentes no universo da periferia desde os anos 70, o hip hop chega, proporcionado pelas trocas em um contexto em que as novidades eram difíceis de serem acessadas. Uma dessas novidades era o break, um dos elementos pertencentes ao hip hop. Com a popularização do break, o universo do hip hop começou a ganhar corpo nos fins dos anos 80, e o rap teve sua primeira coletânea lançada em 88: Hip hop cultura de rua. Com 30 mil cópias vendidas, permitiu que as redes de contatos entre artistas do hip hop se tornassem mais fortes no Brasil, e que a cena ganhasse ainda mais força nos anos 9o, quando o quinto elemento do hip hop - o conhecimento - passou a ser mais presente no movimento e este passou a assumir um viés declaradamente político. Assim, o rap, como canto falado em que a voz do sujeito afrodiaspórico insurge contra uma lógica violenta, performatiza uma série de rupturas ideológicas, estéticas e biopolíticas, construindo seu próprio local e modo de fala.

Para compreender como essas rupturas são operadas no acervo cancional de Criolo e Emicida, partiremos de um cuidado metodológico necessário na análise do corpus: estudar canção está relacionado a atentar-se para as particularidades que envolvem a junção entre linguagem verbal e musical, levando em consideração as potencialidades simbólicas e discursivas presentes nessa relação intersemiótica:

[...] a canção configura-se como artefato cultural a partir da articulação entre duas formas distintas de convenções, as linguísticas e musicais. Esta articulação torna problemática, a meu ver, algo bastante comum aos trabalhos na área de Literatura: a abordagem da letra da canção a partir dos mesmos procedimentos aplicados ao poema. Neste sentido, Luiz Tatit desenvolve um modelo de análise que articula melodia e letra e demonstra o valor da entoação, da palavra em sua relação com diferentes alturas no espaço melódico e que tem sua base no desdobramento de elementos presentes na própria fala. (ALMEIDA, 2008, p.317)

Os rappers, como cancionistas, fazem do canto uma "[...] gestualidade oral, ao mesmo tempo contínua, articulada, tensa e natural, que exige um permanente equilíbrio entre os elementos melódicos, linguísticos, os parâmetros musicais e a entoação coloquial" (TATIT, 2012, p. 9). Essa entoação coloquial, característica marcante da canção brasileira, recebe o nome de figurativização, sendo este um procedimento para fazer com que o texto ganhe naturalidade, como também incorporar o tempo de execução da canção à subjetividade do cancionista. Na figurativização temos uma encenação de cenas e sujeitos, que se corporificam a partir da articulação entre letra e música.

Um dos primeiros aspectos que chamam a atenção no rap é a aproximação maior entre a entoação e a fala, fazendo com que comumente chamemos de "canto falado" o modo de o rapper "mandar a rima", 
ou seja, cantar. Dessa forma, podemos perceber que, no rap, em geral, a figurativização chega ao seu limite:

A passagem do século $X X$ ao $X X I$ foi marcada, no terreno popular, pela explosão do rap, gênero bastante comprometido com a mensagem linguística, e que, portanto, não pode prescindir dos contornos rítmico-melódicos que dão expressividade à letra. Aqui, ao invés, não contamos com precisão no âmbito da sonoridade e muito menos com a escrita que sempre garantiu o registro da forma, por mais complexa que fosse, na música culta. Os autores se apegam antes de tudo a um modo de dizer, ao próprio teor verbal de suas frases e, se aproveitam algumas recorrências musicais, distribuem-nas pelo plano da expressão da letra, gerando rimas e assonâncias que colaboram na memorização dos longos discursos. $O$ resto é força entoativa quase pura que pouco concede aos ritos musicais de estabilização sonora. (TATIT, 2010, p. 14)

A partir da citação de Luiz Tatit, verifica-se a singularidade do rap como canção, em que a figurativização, o "fazer parecer uma situação de comunicação do dia-a-dia" (TATIT, 1986, p.7), é bastante forte. E como ainda se está falando de um gênero musical, esse tensionamento entre canto e fala se articula aos elementos rítmico-melódicos presentes na parte musical (andamento, instrumentos musicais utilizados, samples de outras canções, vocalizes etc.). A forma como a letra está associada ao ritmo fica evidente na encansão dos versos, que acompanham o bum-clap característico do rap, que é a batida do bumbo e da caixa marcando o ritmo da melodia. Nos versos iniciais da canção "Chuva Ácida", de Criolo, podemos verificar essa construção:

Peixes mutantes invadindo o congresso Vomitando poluentes com o logotipo impresso $\mathrm{BR}$, quem é do mangue não esquece

As vítimas perecem, as famílias enlouquecem (CRIOLO, 2016)
As sílabas destacadas nos versos acima coincidem com a marcação da batida da canção e quase todas são as sílabas tônicas. Ao longo da canção, temos, em geral, cada verso correspondendo a um compasso de quatro tempos. Em cada par de compasso, há a presença das rimas, que são tão importantes no rap, refletindo uma correspondência semântica - dentro desse contexto - entre "rimar" e "cantar". Considerando todas as nuances e as possibilidades rítmicas que existem nas canções de rap, destacamos esse padrão rítmico por se tratar de uma batida - ou beat - elemento básico no universo desse estilo musical:

O termo consagrado para falar sobre essa maneira pela qual um MC escande as palavras é "flow". Em inglês, a palavra quer dizer corrente ou fluxo e, metaforicamente, remete à fluidez com que o improvisador encadeira suas rimas. No Brasil, rappers usam ainda o termo "levada", que, além de significar também uma "torrente d'água", tem a particularidade de ser usado por músicos em geral para designar o ritmo do acompanhamento: uma levada de bateria, uma levada de violão. [...]

Quando pensamos no "flow" do rap, estamos falando da maneira sincopada ou suingada de escandir palavras. Um verso de rap é produto de um tipo de ritmo (aquele da linguagem) sendo ajustado a outro (o da música) - algo como uma levada da fala, uma fala cadenciada, ritmada (TEPERMAN, 2015, p. 30).

Na performance ou gestualidade oral do cancionista, temos o encontro e a tensividade estabelecida entre a continuidade e a segmentação da melodia. Vale referir que melodia é uma sucessão de sons: quando falamos da melodia de uma canção, geralmente associamos à sequência de notas, situadas em um ritmo, alturas e durações distintas, que se apresentam na voz que canta. Segundo Tatit (2012), a tensão entre continuidade e segmentação envolve o trabalho com vogais e consoantes em uma canção: a continuidade relaciona-se ao prolongamento das vogais, como os vocalizes, que promovem a passio- 
nalização, uma sugestão de um estado de espírito. $\mathrm{Na}$ tematização, o trabalho com as consoantes permite uma associação maior entre letra e ritmo da canção, dando maior dinamicidade e criando uma ambiência própria à construção discursiva da letra, ou seja, incorporando o tema que a canção traz:

Assim, ao investir na continuidade melódica, no prolongamento das vogais, o autor está modalizando todo o percurso da canção com o /ser/ e com os estados passivos da paixão (é necessário o pleonasmo). Suas tensões internas são transferidas para a emissão alongada das frequências e, por vezes, para as amplas oscilações de tessitura. Chamo a esse processo passionalização. Ao investir na segmentação, nos ataques consonantais, o autor age sob a influência do /fazer/, convertendo suas tensões internas em impulsos somáticos fundados na subdivisão dos valores rítmicos, na marcação dos acentos e na recorrência. Trata-se, aqui, da tematização. (TATIT, 2012, p. 22, grifos do autor)

Criolo e Emicida transitam entre essa batida tradicional do rap e outras bases rítmicas, permitindo a construção de figurativizações diversas e transitando entre o canto falado do rap e o canto musicado presente em outros gêneros musicais. No caso de Criolo, há uma particularidade em seu repertório que coloca em abalo a própria noção de rapper: canções "Não existe amor em SP", "Lion Man”, "Bogotá”, "Freguês da meia noite", "Casa de papelão", Fermento pra massa”, entre outras, estão claramente distanciadas do gênero em que costumamos enquadrar Criolo. Uma consequência dessa característica do repertório do rapper é a amplitude de canções que investem na passionalização, tendo como efeito uma figurativização que não chega ao recrudescimento da figurativização (TATIT, 2010).

A figurativização do rap articula-se ao recorte e à colagem, exercitando o processo de construção identitária dos povos da diáspora, pondo em evidência a impostura e a não aceitação de uma imagem monolítica e tácita de modernidade ou de identidade nacional:
Aliás, o sample (fragmento de uma música incorporado em outra), mais que um recurso para a composição musical é a materialização modelar afrorrizomática, uma vez que, por mais que se identifique de que canção ele foi extraído, ao ser desterritorializado e reterritorializado, retorna em diferença pertencendo à rede que conecta a outros referentes. (FREITAS, 2016, p. 223)

Canções como "Mariô", "Fio de prumo (Padê Onã)" e "Convoque seu Buda", de Criolo, e "Mãe", "Mufete", "Mandume" e "Ubuntu Fristili", de Emicida, são alguns exemplos de trabalhos que colocam em intercâmbio territorialidades múltiplas a partir das referências do universo mítico, religioso e cultural africano e afrobrasileiro, sampleando-as com elementos do cinema hollywoodiano, da filosofia ocidental, dos quadrinhos, das telenovelas etc., negando o reducionismo classificatório e inferiorizante que foi imposto aos povos da diáspora:

A diáspora abala a perspectiva essencializante de unanimidade racial e de tratamento dos negros como se fossem exatamente idênticos, questionando os modelos de classificação que foram usados para os africanos e os afrodescendentes durante a colonização e também após este período, já que ela afeta uma ideia de origem e de identidade únicas, compreendendo o homem e a mulher negros como seres complexos, constituídos de múltiplas raízes, de matrizes diversas e fragmentadas. A África plural encenada aqui é devir e não mais essência ontológica ou signo de um desejo inócuo de retorno do mesmo. (FREITAS, 2016, p. 222, grifo do autor)

Portanto, o rapper tangencia a realidade vivenciada a partir do recorte de elementos da sociedade de consumo, do universo da criminalidade e fragmentos de outras canções. Esse movimento de recorte, apropriação e colagem é uma forma de colher as ruínas ou, "à força", tomar para si objetos culturais e da sociedade de consumo que circulam, contudo são colocados como 
impróprios para sujeitos que historicamente foram alijados de bens de consumo e de produção e, em alguns momentos, tornando-se eles mesmos esses bens.

$O$ trabalho conjunto entre $\mathrm{MC}$ e DJ se manifesta na canção de rap a partir da colagem. O DJ exibe uma forma de composição muito específica, que não parte do uso de instrumentos musicais, mas uma maquinaria que exige não apenas conhecimentos musicais, mas técnicos, por conta do manuseio de programas de edição de áudio e de outras tecnologias. Assim, essas figuras transitam entre o papel de artistas e o de produtores, com um rico acervo tecnológico para inserir efeitos, modulações e simulações, e "[...] quando o equipamento dentro do estúdio se transforma num instrumento musical, 'surge o músico engenheiro de som' para nele compor" (GIUMBELLI, 2008, p. 321). E vale frisar que, com o avanço tecnológico deste último século, mais e mais pessoas passam a montar, em suas próprias casas, seus estúdios, o que é facilitado pela redução de custos, pela gama de equipamentos disponíveis no mercado e pelo aumento da qualidade destes. Com isso, podemos utilizar a categoria "autoprodução" apresentada por Tatiana Bacal (apud GIUMBELLI, 2008) para aqueles que têm seu computador como material de criação, sendo esta categoria uma ação, pelo fato de se considerar todo o processo parte da produção musical, e não uma divisão hierárquica entre composição e produção; não é mais um produtor musical trabalhando em cima de canções ou músicas já estruturadas, mas é ele, ao mesmo tempo, quem capitaneia a composição, a mixagem e a produção.

A mixagem - que vem de mix, mistura - entre diversos fragmentos de sons, cenas e versos dissemina as referências, criando outras além daquelas trazidas da canção da qual saiu o verso enxertado. Sendo o DJ e o MC um múltiplo em sua criação, no trabalho de citação, é como um cirurgião esteta, conforme a analogia feita por Compagnon (1996), em que "[...] a citação é uma cirurgia estética em que sou ao mesmo tempo o esteta, o cirurgião e o paciente [...]" (p. 37-8). Samples, versos e visões se articulam para dar forma a um corpo cuja completude é negada: o rap carrega diversas possibilidades de modulações em cada trecho colado e pode, inclusive, ter em si depositados inúmeros trechos, de durações variadas.

Samplear é deslocar fragmentos e ressignificá-los, promover neles dobras - aberturas que se transformam em caminhos para, no rap, fazer parte dos corpos daqueles que compartilham desse gênero. A tradição oral, que não se documenta e que se fortalece nas suas intermináveis dobras em cada recontar, confronta a força padronizadora e scriptocêntrica das instituições, da tradição e da história para invocar sua força entoativa, seu discurso que se incorpora na fala, no ritmo e na poesia.

A tradição oral é a grande escala da vida, e dela recupera e relaciona todos os aspectos. Pode parecer caótica àqueles que não lhe descortinam o segredo e desconcertar a mentalidade cartesiana acostumada a separar tudo em categorias bem definidas. Dentro da tradição oral, na verdade, o espiritual e o material não estão dissociados. Ao passar do esotérico para o exotérico, a tradição oral consegue colocar-se ao alcance dos homens, falar-lhes de acordo com o entendimento humano, revelar- se de acordo com as aptidões humanas (KI-ZERBO apud FREITAS, 2016, p 40).

Partindo para a análise de canções, em "Chuva Ácida", de Criolo, vemos a tematização como procedimento preponderante no rap, como forma de incorporar à canção o ataque discursivo que é próprio desse gênero musical. Os golpes discursivos associados às questões ambientais associam-se às cenas apresentadas nas letras, destacando o peso dos verbos e de suas cargas semânticas voltadas a ações. A seguir, a letra completa da canção, para que possamos analisá-la.

Peixes mutantes invadindo o congresso Vomitando poluentes com o logotipo impresso $B R$, quem é do mangue não esquece As vítimas perecem, as famílias enlouquecem O caranguejo gigante decepando seus corpos Aniquilar suas famílias, jogá-las aos corvos Garças bizarras movidas a óleo, sem dó e sem dor 
Bicando seus olhos, sobrevoando em campos Uma seleção de mortos, pensamentos mórbidos (não)

Realidade, carne e ossos

Enquanto ser humano eu vou destruindo o que posso

O elevador aqui só desce, o demônio é meu sócio

\section{Abriram (uuh) a caixa de pandora}

Saimon diz: Saiam agora!

A chuva espalhando, todos os mares

Ai ai, uiui (uiuiuiui), ai como isso arde

É bateria de celular, césio, similares

A peste invisível maculando os ares

Mercúrio nos rios, diesel nos mares

O solo estéril, é já fizeram sua parte

Uuh ó e salvem o planeta

É papelzinho de bala no chão tio é muita treta

O sádico monstro está à frente

Sai do círculo vicioso e recicla sua mente (vamo estudar pô!)

Minha rima é voraz, árdua e quente

O crioulo aqui é doido e os planos são dementes

E o futuro é num piscar de olhos, cê tá sabendo?

Fulano ali tá derretendo

Eles ficam assim, olhando pra mim

Terceiro setor, vem que tem dindim

Vendem a ideia de que são legais

Nadar de costas vai jacaré abraça!

Num universo de horrores, tuberculose

Câncer, tumores, chagas que a prata não repara

Vidas cujo respeito não viram nada

O homem sendo a imagem da besta

Crack é fichinha, estão destruindo o planeta

Em breve nascerão vacas sem tetas
Nos cafezais, milharais, a praga dominando a colheita

A água que é pouca sumirá totalmente Suas sacolas de dinheiro

Não comprarão só copo de aguardente Porque destruíram a cana que adoça os doces Que adoça o amargo da vida Olhar em volta e ver tanta burrice reunida Vamos parar com isso Aprender sobre a coleta seletiva de lixo Arqueólogos, geólogos, antropólogos (aah) Façam parte dos nossos Respeito e instrução ao povo Para dizerem sim eu posso, sim eu posso, hoy, sim eu posso

Senhores do orgulho

Abutres comerão suas tripas no entulho As nuvens vão se formando, as gotas deteriorando

São as pernas quentes da morte aos poucos Aos poucos, aos poucos nos carregando

Eles ficam assim, olhando pra mim Terceiro setor, vem que tem dindim Vendem a ideia de que são legais Nadar de costas vai jacaré abraça! (CRIOLO, 2016)

Na versão de 2016 do álbum Ainda Há Tempo, a canção inicia com uma voz feminina, pedindo justiça, fazendo menção ao desastre em Mariana e reforçando a atualidade e a urgência envolvendo a degradação do meio ambiente. Após essa fala, é dado início à parte instrumental, que apresenta poucos elementos e poucas variações melódicas, o que demonstra uma linha mais old school de Criolo nessa canção. Isso fica evidente também na pouca variação de altura ${ }^{2}$ ao longo da canção: é possível verificar que a pouca variação na altura serve para destacar as sílabas tônicas e, consequentemente, o beat da canção, já que algumas

2 Segundo Bohumil Med (1996), a altura é "determinada pela frequência das vibrações, isto é, da sua velocidade. Quanto maior for a velocidade da vibração, mais agudo será o som." É importante não confundirmos o conceito de altura em teoria musical com volume, o que comumente é feito. 
dessas variações se encontram nas sílabas fortes. Com esse recurso, a articulação entre ritmo, poesia e mensagem é contundente, pelo fato de a figurativização no canto falado estar ligada ao discurso de protesto, já anunciado no sample que abre a canção.

Articulada a essa característica referente à altura, predomina na canção a tematização, que se evidencia na segmentação promovida pelas consoantes. A abordagem da letra, já anunciada em seu título, reforça a "secura" e o impacto que a tematização apresenta, o que é explicitado pelo enunciador em "Minha rima é voraz, árdua e quente", adjetivos distanciados de um campo semântico ligado à leveza ou suavidade. Ainda que no refrão tenhamos uma maior variação de altura e um certo prolongamento das vogais, tais estratégias trabalham em função da tematização predominante na canção, inclusive trazendo uma perspectiva que é ao mesmo tempo do enunciador, mas também colocada como se outro sujeito estivesse sendo o enunciador. Tal aspecto pode ser observado pelo fato de o refrão ter a voz de Criolo alternada com backing vocals e, no primeiro verso do refrão, termos a indicação de que há um grupo que julga esse eu-lírico. O refrão incorpora a voz coletiva que entoa o enfrentamento a um modo de o capitalismo se desenvolver dando continuidade à destruição do meio ambiente, porém mascarando essa prática com o discurso da sustentabilidade, como é percebido em "Terceiro setor, vem que tem dindim". O uso de uma estrutura com traços de passionalização e com variações de alturas um pouco mais frequentes fazem com que essa voz individual do eu-lírico seja escutada junto a outras, como um coro.

Na segunda parte da canção, percebe-se uma aproximação ainda maior da fala cotidiana na entoação de Criolo, iniciada no verso "Nos cafezais, milharais, a praga dominando a colheita". Além de um maior distanciamento do uso das rimas para a articulação entre versos, há um distanciamento da associação entre ritmo e métrica, o que provoca um destaque ainda maior na mensagem que é trazida no trecho - a convocação para uma mudança de postura. O uso da tematização no rap, portanto, está vinculado ao quinto elemento do hip hop, ao conhecimento: na perspectiva mais tradicional do rap, o canto falado é uma estratégia para que a "mensagem" seja transmitida com mais clareza, além de estar mais apropriada às temáticas recorrentes nesse gênero musical, como o racismo, a desigualdade social e a violência policial, por exemplo.

Direcionando para a canção do outro rapper do corpus, na primeira parte da canção "Levanta e Anda", de Emicida, destacada a seguir, também podemos perceber a tematização e a passionalização operando ambiências distintas na canção, ao mesmo tempo que reforçam o discurso presente na letra:

Era um cômodo, incômodo, sujo como dragão de komodo

Úmido, eu homem da casa aos seis anos

Mofo no canto, todo, TV, engodo, pronto pro lodo

Tímido, porra, somos reis, mano

Olhos são eletrodos, sério, topo, trombo corvos Num cemitério de sonhos, graças a leis, planos Troco de jogo, vendo roubos, pus a cabeça a prêmio Ingênuo, colhi sorrisos e falei -- vamos! É um novo tempo, momento pro novo, ao sabor do vento

Me movo pelo solo onde reinamos Pondo pontos finais na dor, como Doril, Anador

Somos a luz do senhor, pode crer, tamo Construindo, suponho não, creio, meto a mão

Em meio à escuridão, pronto, acertamos Nosso sorriso sereno hoje é o veneno Pra quem trouxe tanto ódio pr'onde deitamos

Quem costuma vir de onde eu sou Às vezes não tem motivos pra seguir Então levanta e anda Mas eu sei que vai, que o sonho te traz Coisas que te faz prosseguir Levanta e anda (EMICIDA, 2013) 
Seguindo a mesma estratégia presente em "Chuva Ácida”, de Criolo, a canção de Emicida possui uma modulação diferente quando comparamos o refrão com os demais trechos. Na estrofe inicial, a articulação entre a recorrência do fonema / k/, consoantes explosivas e oclusivas e as vogais fechadas constroem a cena em que a voz que canta se insere. As vogais fechadas favorecem a estabilidade de altura nas sílabas e reforçam o impacto que as consoantes carregam, como podemos perceber logo no primeiro verso. A figurativização ganha força com o trabalho dos fonemas consonantais, que se tornam batidas, golpes que marcam o corpo do sujeito enunciador e que ele, no vivido da canção, ressignifica e devolve, seja como um imperativo - "levanta e anda, vai!" -, seja como uma resposta a contrapelo do que o racismo e a história oficial brasileira impõem ao negro - "Somos reis, mano". As batidas associadas à letra, como tapas na face da audiência, associadas ao imperativo "levanta e anda", são realçadas a partir da tematização, que desenha a voz que canta a partir da figurativização de um sujeito que, a todo momento, está ciente da sua força e que, ao observar seu passado, tira dele forças para continuar.

O momento da passionalização, que fecha a canção, está também presente no verso "Somos maior, nos basta só sonhar, seguir": o prolongamento das vogais, destacado pela presença do rapper Rael da Rima como convidado de Emicida, realça esse estado de alma que também é mensagem, também é conhecimento. Além desse verso, no refrão, também cantado por Rael, a passionalização está presente no prolongamento da vogal /i/ nas palavras "seguir" e "prosseguir", articulados aos sentidos construídos pela letra, relacionados à postura ativa e de enfrentamento que os afrobrasileiros precisam carregar para enfrentar a sociedade brasileira.

A referência ao mito bíblico de Lázaro, sujeito dado como morto e que revive a partir da palavra de Jesus Cristo, é associada ao canto falado do rap, que, pela figurativização do afrobrasileiro que é, pela lógica socioeconômica brasileira, deixado para morrer, levanta e anda a partir do rap, ou seja, a partir da palavra (en) cantada, ressignifica sua história individual e coletiva, e a alternância entre tematização e passionalização permite o trânsito entre essa memória individual e ao mesmo tempo coletiva que perpassa o corpo afrobrasileiro, a partir dessa coletividade invocada pela voz que canta, presente, por exemplo, no "Somos reis, mano". A voz revive o passado histórico em que muitos africanos escravizados eram de famílias reais em suas nações, rasurando o passado que enclausura a imagem do africano ao escravo, e, ao mesmo tempo, com o vocativo "mano" - irmão -, constrói uma correspondência com aquele que escuta a canção e se vê na figurativização presente nela. E quando o refrão investe na passionalização, temos Emicida e Rael trabalhando com procedimentos diferentes para afetar esse corpo que escuta e se vê na canção.

A figurativização como forma de fazer o canto parecer natural, por meio desse jogo tensional entre passionalização e tematização, estabelece uma verdade enunciativa, que é extremamente valorizada no contexto do rap: a "mensagem", ou ainda, a crítica vinculada a um despertar de consciência deve estar incorporada à canção, portanto, forma e conteúdo, dicotomias tão questionadas na contemporaneidade, mais uma vez se dissolvem nesse terreno da palavra poética e cantada, em que o "como dizer" está intimamente vinculado ao "o que dizer".

Tudo ocorre como se, pela narrativa, tivéssemos uma experiência de vida bem circunscrita, pronta para ser fisgada pela melodia. Ou, de outro enfoque, é como se a narrativa traduzisse, nos termos da inteligibilidade, a singularidade da emoção descrita nas curvas melódicas. Não é por acaso que a complementaridade entre narrativa e melodia sempre esteve presente não apenas no terreno da canção mas também na ópera, no teatro, na dança, no cinema, na novela de televisão etc. (TATIT, 2012, p. 25)

Entender o papel político da arte é considerar uma forma diferente de trabalho com a linguagem, como, no caso do rap, é a linguagem lírica e musical. Pensando o contexto musical brasileiro e reiterando nossa concepção de pensar a canção brasileira como um campo 
propício para discussões teóricas sobre a lírica contemporânea, trazemos a seguinte afirmação de Santuza Cambraia Naves, acerca dos anos 60 no Brasil:

[...] a canção popular tornou-se o lócus por excelência dos debates estéticos e culturais, suplantando o teatro, o cinema e as artes plásticas, que constituíam, até então, o foro privilegiado dessas discussões. Os compositores populares, de maneira semelhante aos músicos modernistas, como é o caso de Heitor Villa-Lobos, passaram a comentar todos os aspectos da vida, do político ao cultural, tornando-se "formadores de opinião". Esse novo estatuto alcançado pela canção contribuiu para que o compositor assumisse a identidade de intelectual num sentido mais amplo do termo. (NAVES, 2010, p. 19)

A partir das afirmações de Santuza Naves, destacamos o papel de artistas como Criolo e Emicida não apenas no contex to do hip hop, mas no cenário da canção popular urbana brasileira. Por conseguinte, o modo como os artistas constroem suas obras está relacionado a uma compreensão multifacetada do Brasil, que desloca e rasura discursos para fazer do rap uma possibilidade de fala e de ação dos afrobrasileiros. O recorte e a colagem, desorganizam as tradições para organizar sujeitos que, pela canção, impõem-se de modo afirmativo, fazendo do flow um processo ético e estético.

Criolo e Emicida apresentam em suas canções possibilidades de fazer do espaço artístico o terreno da diferença, de fazer da impostura um modo de rasurar discursos tradicionais e vozes hegemônicas, é a lição que a história monumental não é capaz de ensinar. Educar pelo sentimento e pelas alteridades - e não pela doxa, pelo modelo, pelo fechamento. Esse não-fechamento se manifesta no processo de composição, em que MCs e DJs, como farejadores de sonoridades, exercitam a multiplicidade a partir da performatização de identidades múltiplas no rap, confrontando as origens que categorizam e enquadram a imagem do afrobrasileiro em representações cristalizadas. Desse modo, em lugar dos discursos tradicionais que invisibi- lizaram ou impuseram sobre o corpo negro a marca do inferior, o rap produz devires para esse corpo e para a sociedade brasileira pela via do múltiplo, registrando a sua marca a música popular brasileira.

\section{Referências}

ALMEIDA, Tereza Virginia. O corpo do som: notas sobre a canção. In: MATOS, Cláudia Neiva de; TRAVASSOS, Elizabeth; MEDEIROS, Fernanda Teixeira de (org.). Palavra cantada: ensaios sobre poesia, música e voz. Rio de Janeiro: 7Letras, 2008. p. 316-325. https://doi. org/10.1353/lbr.0.0100

COMPAGNON, Antoine. O trabalho da citação. Trad. Cleonice P. B. Mourão. Belo Horizonte: Editora UFMG, 1996.

DERRIDA, Jacques. A escritura e a diferença. 3. ed. São Paulo: Perspectiva, 2005.

FREITAS, Henrique. O arco e a arkhé: ensaios sobre literatura e cultura. Salvador: Ogum's Toques Negros, 2016. https://doi.org/10.24261/2183-816×1326

GILROY, Paul. O Atlântico Negro: modernidade e dupla consciência. São Paulo: ed. 34; Rio de Janeiro: Universidade Candido Mendes, Centro de Estudos Afro-Asiáticos, 2001. https://doi.org/10.1590/s0101$546 \times 2002000200008$

GIUMBELLI, Emerson; DINIZ, Júlio César Valadão; NAVES, Santuza Cambraia (org.). Leituras sobre música popular: reflexões sobre sonoridades e cultura. Rio de Janeiro: 7Letras, 2008.

MED, Bohumil. Teoria da música. 4. ed. rev. e ampl. Brasília, DF: Musimed, 1996.

MUNIZ, Bruno Barboza. Dub: um estilo? Um gênero? Um vírus? Rio de Janeiro: /PPGSA, 2010. (Dissertação) - Programa de Pós-Graduação em Sociologia e Antropologia, IFCS, UFRJ, Rio de Janeiro, 2010. https://doi.org/10.17771//pucrio.acad.4488

NAVES, Santuza Cambraia; COELHO, Frederico Oliveira; BACAL, Tatiana (org.). A MPB em discussão: entrevistas. Belo Horizonte: UFMG, 2006.

NAVES, Santuza Cambraia. Canção popular no Brasil:a canção crítica. Rio de Janeiro: Civilização Brasileira, 2010. 
SANTOS, Rosana Aparecida Martins. O estilo que ninguém segura. Mano é mano! boy é boy! boy é mano? mano é mano? Reflexão crítica sobre os processos de sociabilidade entre o público juvenil na cidade de São Paulo na identificação com a musicalidade do rap nacional. (Dissertação de Mestrado) - Escola de Comunicação e Arte, Universidade de São Paulo, São Paulo, 2002. https://doi.org/10.11606/d.27.2002. tde-10102006-170247

TATIT, Luiz. A canção e as oscilações tensivas. Estudos Semióticos, São Paulo, v. 6, n. 2, p. 14-21, nov. 2010. Disponível em: http://www.fflch.usp.br/dl/semiotica/ esi. Acesso em: 15 abr. 2017. https://doi.org/10.11606/ issn.1980-4016.esse.2010.49266

TATIT, Luiz. A canção: eficácia e encanto. São Paulo: Atual, 1986.

TATIT, Luiz. O cancionista. Composição de canções no Brasil. 2. ed. 1. reimp. São Paulo: EDUSP, 2012.

TEPERMAN, Ricardo. Se liga no som: as transformações do rap no Brasil. São Paulo: Claro Enigma, 2015.

VIANNA, Hermano. Filosofia do Dub. Folha de São Paulo. Caderno Mais!, São Paulo, 9 nov. 2003.

\section{Discografia}

CRIOLO. Ainda Há Tempo. 2016a. Disponível em: http://www.criolo.net/. Acesso em: 25 jan. 2017.

EMICIDA. O glorioso retorno de quem nunca esteve aqui. São Paulo: Laboratório Fantasma, 2013.

Recebido em: 17/10/2018

Aceito em: 29/04/2019 